\title{
Clinical results with human gonadotrophins in anovulation, using two alternative dosage schemes
}

\author{
J. K. BUtLER \\ M.A., M.B., B.Chir., D.R.C.O.G. \\ G. D. Searle \& Co. Ltd, Lane End Road, High Wycombe, Bucks.
}

THE fear of many clinicians is that the treatment of infertile women with gonadotrophins is very complicated and is almost certain to lead to multiple pregnancy and ovarian cyst formation. One of the aims of this communication will be to dispel some of these fears by discussing a rationalized approach to therapy, dealing with the choice of patients, their practical management and giving some indication of the results which may be expected.

\section{Source of materials}

Only human gonadotrophins will be considered since animal preparations such as pregnant mares serum or sheep pituitary extracts are no longer regarded as acceptable where repeated administration may be required. This is because the formation of neutralizing antibodies to the foreign protein leads to a declining response as treatment proceeds and the danger of anaphylaxis may also be present. It has however recently been suggested by Swyer et al. (1968) and Shearman (1964) that pregnant mares serum may have a place in the investigation of anovulatory patients where they recommend its use in diagnostic tests.

Human chorionic gonadotrophin (HCG) was the first gonadotrophin to be extracted and purified from human material, namely pregnancy urine. The biological activity of HCG is very similar to that of LH and its use alone in the treatment of infertility is rarely indicated, being restricted theoretically to cases where there is a specific defect of $\mathrm{LH}$ release in the presence of normal follicular maturation. It is however used routinely following FSH-containing gonadotrophin preparations.

In patients with anovulation due to gonadotrophin deficiency or a deficient ovarian response to an apparently normal pituitary drive, treatment will require gonadotrophin preparations with a predominant FSH activity to bring about follicular stimulation and maturation followed by LH or HCG to induce ovulation and corpus luteum formation. Human FSH is now available in the form of human pituitary gonadotrophin (HPG) derived from postmortem pituitary glands and human menopausal gonadotrophin (HMG) which is extracted from post-menopausal urine.
The clinical use of HPG was first described by Gemzell (1958) and has since been reported by many authors including Brown et al. (1969), Buxton, Kase \& Van Orden (1963), Crooke et al. (1963), Crooke, Butt \& Betrand (1966), Gemzell, Diczfalusy \& Tillinger (1958), Gemzell (1964), Gemzell \& Roos (1966), Gemzell et al. (1970), Pennington \& Hall (1967), Shearman (1969) and Townsend et al. (1966). Although HPG is in continuing use in a number of academic centres, the difficulties involved in the collection and processing of post-mortem pituitary glands impose considerable limitations which make it unlikely that gonadotrophins from this source could become generally available.

Gonadotrophins are normally excreted in the urine in a form which is still biologically active and the concentration rises considerably after the menopause when the ovarian feedback is no longer operative. Attention was drawn by Borth, Lunenfeld \& DeWatteville (1954) to the possibility of using post-menopausal extracts in the treatment of infertility and this has proved to be a convenient source of gonadotrophins for clinical use. The usage of HMG throughout the world has led to a considerable literature but extensive experience has been reported by Kase, Mroueh \& Buxton (1968), Pasetto \& Montanino (1967), Rabau et al. (1967), Roland (1969) and Vande Wiele \& Turksoy (1965). HMG is available as Pergonal in the U.K. and many other countries and the results to be discussed later relate to this material.

There is evidence that HMG and HPG differ chemically in their amino-acid content (Butt, 1970) and immunologically (Taymor \& Tamado, 1967). It seems clear however that the two materials are biologically indistinguishable in clinical practice (Crooke, 1970; Diczfalusy et al., 1964).

Materials for clinical use contain mainly FSH together with a small but essential amount of $\mathrm{LH}$. Each ampoule of Pergonal contains $75 \mathrm{IU}$ each of FSH and LH but this should not be taken to mean that the material is an equal mixture of the two hormones, since the units are not comparable.

The question of what is the ideal FSH/LH ratio for clinical preparations of gonadotrophin has received some attention in recent years without any 
definitive conclusion being reached. It has been indicated that preparations with a very low $\mathbf{L H}$ content are less effective than those with a $1: 1$ ratio (Jacobsen \& Marshall, 1969 and Jones et al., 1969) and some earlier work on rodents reported by Lostroh \& Johnson (1966) and Eshkol et al. (1967) has shown that relatively pure FSH fails to induce uterine growth in hypophysectomized animals although follicular development proceeds normally. This is taken to indicate that $\mathbf{L H}$ is essential for normal steroidogenesis in the developing follicle.

Since gonadotrophins are proteins, it is of course essential to give them by injection and this is normally by the intramuscular route.

\section{Selection of patients}

HPG and HMG are used in conjunction with HCG to induce ovulation in women with infertility due to anovulation. There are no absolute contraindications to treatment but patients selected should meet the following criteria:

(1) Have a positive indication, i.e. they should wish to become pregnant and have proven anovulation.

(2) Have a fertile or potentially fertile partner.

(3) Have potentially responsive ovaries, i.e. ovarian agenesis or dysgenesis should be excluded in primary amenorrhoea and an early menopause should be excluded in secondary amenorrhoea.

(4) Have genitalia organically compatible with fertility-normal vagina and uterus, patent Fallopian tubes.

(5) Have no evidence of untreated endocrine disorders such as myxoedema, pituitary tumour or adrenal disease which may lead to anovulation.

One will frequently need to consider whether to use gonadotrophins as the first line of treatment or whether to treat the patient first with clomiphene citrate or a similar preparation and to proceed to gonadotrophins only if pregnancy is not achieved. Although there are no simple criteria to assist this choice, there are a number of factors which may influence the decision.

Gonadotrophins must be given by injection whereas clomiphene citrate is orally active. Their administration is more exacting and it is essential to monitor the response carefully for full efficiency and to avoid overstimulation with the possible consequence of multiple pregnancy or ovarian cyst formation.

On the other hand gonadotrophins have a broader clinical application and will undoubtedly promote ovulation in many women who will not respond to clomiphene citrate simply kecause one is providing 'replacement therapy' rather than relying on the ability of the patient's pituitary to release endogenous gonadotrophins.
Since clomiphene citrate will only be effective in the presence of a responsive pituitary, it is likely to be more effective in women with oligomenorrhoea or secondary amenorrhoea who are relatively well oestrogenized than those with primary amenorrhoea or long standing secondary amenorrhoea where endogenous oestrogen production is poor. Bell \& Loraine (1967) have demonstrated that the urinary oestrogen excretion is a useful discriminating factor-patients excreting less than $10 \mu \mathrm{g}$ of total oestrogen/24 hr being less likely to respond to clomiphene citrate than those excreting more than $10 \mu \mathrm{g}$.

\section{Monitoring the response to treatment}

HMG or HPG are used to stimulate follicular development over a period of 8 days or more, when HCG is given to trigger ovulation and formation of the corpus luteum. There is however a considerable variation in the individual responsiveness to gonadotrophins. This means that the use of a standard dose will lead on the one hand to inefficient treatment where some patients receive a subtherapeutic dose and on the other hand will introduce the danger of excessive response in the most 'sensitive' patients which may manifest as multiple pregnancy or ovarian cyst formation.

It is therefore considered necessary to individualize the dosage in each patient and this in turn wile require the use of methods to assess the response.

Before considering the methods of monitoring, it is useful to discuss the results of over-treating with gonadotrophins. An excessive dose of HMG or HPG will probably lead to the formation of follicular cysts which are usually small and symptomless, although they may be detectable on vaginal examination. If however, one fails to recognize the excessive follicular response and HCG is given, there is a definite risk of multiple pregnancy and of the formation of luteal cysts which are generally much larger and more vascular than follicular cysts. When these are sufficiently large they will cause pelvic discomfort and lower abdominal distention-a situation usually described as 'mild hyperstimulation'. Occasionally these luteal cysts are associated with the formation of ascites and even pleural effusion when the condition is referred to as "severe hyperstimulation'. Secondary fluid shifts may then rarely result, including haemoconcentration and shock. These problems and their management have been discussed by Mozes et al. (1965), Polishuk \& Schenker (1969), Sele \& Starup (1970) and Tyack \& Ellis (1971).

Monitoring of the follicular response to HMG or HPG therefore has two purposes. Firstly, to identify the excessive response so that HCG may be withheld, thereby avoiding the risk of hyperstimulation. The second purpose is to promote 
optimum efficiency of treatment by ensuring that adequate HMG or HPG is given to provoke a useful response. A third role will apply when using dosage regimens of variable duration to provide an indication of the best time to give HCG.

The alternative approaches to monitoring are biochemical and clinical, although the ideal is undoubtedly a combination of the two. Oestrogen assays provide the most precise assessment of the level of ovarian response-usually by means of 'total oestrogen' assays on 24-hr urine samples.

A clinical assessment of changes in oestrogen levels may be attempted by examining changes in vaginal cytology and the cervical mucus. In practice, vaginal cytology is not ideal for monitoring. Johannison, Gemzell \& Diczfalusy (1961) have shown a good correlation between karyopyknotic index and urinary oestrogen levels at the lower end of the range but the correlation becomes progressively poorer at higher oestrogen levels. Cytology could therefore be useful in showing that a response to gonadotrophins has occurred but would be unreliable as an indication of excessive response.

The cervical mucus undergoes a number of changes as oestrogen levels increase-these include an increase in quantity and lowered viscosity (demonstrated by an increasing Spinnbarkeit) whilst the appearance of dried mucus on a glass slide under the low-power microscope changes from a 'cellular' pattern to a 'fern' pattern. None of these changes are more than semi-quantitative and Insler has for instance shown that the ferning pattern may be fully developed in mucus from patients where the urinary total oestrogen level is only $20 \mu \mathrm{g} / 24 \mathrm{hr}$, which is below the usual ovulatory level reached in a spontaneous cycle, and well below the levels where hyperstimulation may be imminent.

It is therefore clear that the clinical tests may be used to demonstrate a response to treatment but they will be less reliable than oestrogen assays in identifying excessive responses.

\section{The alternative approaches to gonadotrophin adminis- tration}

The methods of administering gonadotrophins will be discussed only in general terms without details of day-to-day management which will be available from the manufacturers of the materials used.

The standard method of giving HMG or HPG has been on a daily basis using either a fixed dosage as recommended by Thompson \& Hansen (1970) or a variable dose level as described by various authors including Rabau et al. (1967). Daily injections are given until the desired clinical or biochemical response is seen, when the HMG or HPG is stopped and one or more injections of HCG are given. The duration of treatment is variable, depending on the response, which complicates the problem of monitoring and in particular, daily attendance at hospital (including week-ends) puts considerable demands on the patient and on those treating her.

For these reasons, we looked for a simpler scheme which would be at least equally effective and safe but would impose less demands on the patient and those responsible for her care. The eventual choice was a scheme in which three injections of HMG are given on alternate days followed by HCG on day 8commonly referred to as the $1 / 3 / 5$ scheme. The steps leading to this choice have been described by the author (Butler, 1969). The $1 / 3 / 5$ scheme was shown to induce an oestrogen excretion pattern similar to that seen in the pre-ovulatory phase of the normal cycle and this was consdered a good reason to investigate its clinical effectiveness.

The advantage of the $1 / 3 / 5$ scheme is that the response is predictable in terms of timing, and monitoring may be limited to urinary oestrogen assays on days 1,6 and 8 together with clinical examination on days 1 and 8. (The days are arbitrary, day 1 being the first day of treatment.) It is important to have the result of the day 6 oestrogen assay when the patient is seen on day 8 since this will determine whether or not HCG should be given. This would have been difficult until recently but the newer rapid assays, as described by Brown (1968), make this perfectly feasible.

In practical terms the $1 / 3 / 5$ scheme requires the patient to attend an out-patient clinic on a certain day when treatment is begun. She is provided with urine containers and instructions, and arrangements are made for further injections on days 3 and 5. She attends the clinic again on the same day next week (day 8) when HCG will be given if the oestrogen response is not excessive.

\section{Results of treatment with HMG (Pergonal)}

A number of clinicians in the U.K. who have been using HMG (Pergonal) have kindly made their results available and Table 1 shows the overall results on the daily dosage and the $1 / 3 / 5$ scheme.

It is clear from this table that there is a remarkable similarity between the rates of ovulation, pregnancy and hyperstimulation with the two dosage schemes. It should be mentioned that the pregnancy rate per patient is artificially low because the data include many patients who are in the early stages of treatment, many of whom will undoubtedly become pregnant at a later stage.

The hyperstimulation rate is approximately $5 \%$ with both schemes. The mild hyperstimulations consist only of mild abdominal distension or discomfort and call for no treatment so they are of no real clinical importance. The three severe hyper- 
TABle 1. Overall results of Pergonal treatment in the U.K.

\begin{tabular}{|c|c|c|c|c|c|}
\hline & \multicolumn{2}{|c|}{ Daily dosage } & \multicolumn{3}{|c|}{$1 / 3 / 5$ dosage } \\
\hline & Number & $\%$ & Number & & $\%$ \\
\hline $\begin{array}{l}\text { Patients } \\
\text { Courses } \\
\text { Ovulations } \\
\text { Pregnancies } \\
\text { Hyperstimulation }\end{array}$ & $\begin{array}{r}174 \\
424 \\
226 \\
41 \\
21 \text { mild }\end{array}$ & $\begin{array}{c}- \\
53 \quad \text { (courses) } \\
22 \cdot 4 \text { (patients) } \\
5 \cdot 0 \text { (courses) }\end{array}$ & $\begin{array}{l}269 \\
856 \\
398 \\
85 \\
39 \text { mild } \\
3 \text { severe }\end{array}$ & $\begin{array}{l} \\
47 \\
28 \\
4 \cdot 6 \\
0 \cdot 35\end{array}$ & $\begin{array}{l}- \\
\text { (courses) } \\
\text { (patients) } \\
\text { (courses) } \\
\text { (courses) }\end{array}$ \\
\hline
\end{tabular}

TABLe 2. Outcome of pregnancies following Pergonal

\begin{tabular}{|c|c|c|c|c|}
\hline & \multicolumn{2}{|c|}{ Daily dosage } & \multicolumn{2}{|c|}{$1 / 3 / 5$ dosage } \\
\hline & Number & $\%$ & Number & $\%$ \\
\hline \multicolumn{5}{|l|}{ Abortions } \\
\hline 1st trimester & 4 & 22 (pregnancies) & 13 & 21 (pregnancies) \\
\hline 2nd trimester & 5 & - & 5 & - \\
\hline Stillbirths & 2 & - & 6 & - \\
\hline \multicolumn{5}{|l|}{ Live births } \\
\hline Single & 18 & - & 33 & - \\
\hline Multiple & 10 & 36 (live births) & 19 & 37 (live births) \\
\hline Still pregnant & 3 & - & 9 & - \\
\hline Total & 41 & 一 & 85 & - \\
\hline
\end{tabular}

stimulations which occurred with the $1 / 3 / 5$ scheme are more worrying but it could well be argued that all of these were avoidable. In one, the total urinary oestrogen level on day 6 was $460 \mu \mathrm{g}$, whereas it is suggested that $140 \mu \mathrm{g}$ is the limit above which HCG should be withheld. In another the oestrone excretion on day 7 was $77 \mu \mathrm{g}$ which is rather high but the patient already had ovarian enlargement which could have been regarded as a danger signal. In the third case, the total oestrogen excretion was $120 \mu \mathrm{g}$ on the day when HCG was given but the particular laboratory doing the assay was known to produce results consistently below the expected figures and the methodology may have been suspect.

Table 2 shows the outcome of the pregnancies following the two dosage schemes and again there is a remarkable similarity in the figures. The abortion rate of $21-22 \%$ is in agreement with most reports on ovulation induction with gonadotrophins or clomiphene citrate. The multiple pregnancy rate of $36-37 \%$ is high compared with some reports but it should be borne in mind that most reports of large series are from centres with many years experience of ovulation induction.

Relative 'efficiency' of daily dosage and $1 / 3 / 5$ dosage An analysis has been made of the number of courses and the number of ampoules of HMG required to achieve pregnancy. The analysis considers only patients who did become pregnant and only includes first pregnancies.
The figures relate to ampoules of HMG (Pergonal) 80 each of which contains 75 IU of FSH and approxis mately 75 IU of LH.

Table 3 illustrates the results of this analysis on twenty-one pregnancies following daily dosage and fifty-eight pregnancies following $1 / 3 / 5$ dosage. Statistical analysis by the Mann-Whitney Ranking Test indicates that the $1 / 3 / 5$ dosage is a significantly more economical method of inducing pregnancy, both with respect to the total number of ampoules used (including non-effective courses), where the significance reaches the $5 \%$ level of probability and also with respect to the number of ampoules used in the course leading to pregnancy (significant at the $5 \%$ level of probability).

Results of Pergonal treatment in patients previously treated with clomiphene citrate

The data available include 222 patients who had previously been treated with clomiphene citrate. These obviously form a selected group, being mainly patients who failed to respond adequately, so no comparison between the effectiveness of the two treatments is implied.

It is however clear from Table 4 that good results can be anticipated with HMG in patients who have shown a poor response to clomiphene citrate.

\section{Conclusions}

No attempt has been made to explain the detailed day-to-day management of a patient on gonado- 
TABLE 3. Efficiency of treatment in the patients who achieved pregnancy for the first time

\begin{tabular}{|c|c|c|c|}
\hline & Daily dosage & $1 / 3 / 5$ dosage & $\begin{array}{l}\text { Statistical comparison } \\
\text { by the Mann-Whitney } \\
\text { Ranking Test (two-tailed) }\end{array}$ \\
\hline Pregnancies & 21 & 58 & 一 \\
\hline $\begin{array}{l}\text { Number of courses/ } \\
\text { pregnancy }\end{array}$ & $\begin{array}{cl} & 2 \cdot 6 \\
\text { (range } 1-10)\end{array}$ & $\begin{array}{c}2 \cdot 4 \\
\text { (range } 1-9 \text { ) }\end{array}$ & $\begin{array}{l}\text { No significant } \\
\text { difference } \\
(P<0.55)\end{array}$ \\
\hline $\begin{array}{l}\text { Mean number of ampoules } \\
\text { used/pregnancy }\end{array}$ & $\begin{array}{c}46 \\
\text { (range } 10-133 \text { ) }\end{array}$ & $\begin{array}{c}37 \\
\text { (range } 9-141 \text { ) }\end{array}$ & $\begin{array}{l}1 / 3 / 5 \text { dosage } \\
\text { significantly } \\
\text { more economical } \\
\quad(P<0.05)\end{array}$ \\
\hline $\begin{array}{l}\text { Mean number of ampoules used } \\
\text { in the course leading to pregnancy }\end{array}$ & $\begin{array}{l}23 \\
\text { (range } 10-45)\end{array}$ & $\begin{array}{c}17 \\
\text { (range } 9-45)\end{array}$ & $\begin{array}{l}1 / 3 / 5 \text { dosage } \\
\text { significantly } \\
\text { more economical } \\
(P<0.05)\end{array}$ \\
\hline
\end{tabular}

TABLE 4. Effect of Pergonal in 222 patients previously treated with clomiphene citrate

\begin{tabular}{lcc}
\hline & Ovulation & Pregnancy \\
\hline Response to clomiphene citrate & 55 & 4 \\
Response to Pergonal & 156 & 68 \\
\hline
\end{tabular}

trophins-this information is available from the makers of the respective preparations.

The aim has been to offer an introduction to the subject and to indicate the results which may be anticipated in suitably chosen patients.

In particular, a revised method of using HMG is suggested which offers considerable advantages in terms of convenience. The results indicate that this dosage scheme, in which three injections of HMG are given on alternate days, is at least as effective as the more commonly employed daily dosage and it also appears to be a more economical method of achieving pregnancy.

\section{Acknowledgments}

The author is grateful to the various clinicians who have made their data available for study and to $\mathrm{Mr}$ M. J. C. Howard and Miss M. E. Stratford for their help with the analysis.

\section{References}

Bell, E.T. \& Loraine, J.A. (1967) Recent Research on Gonadotrophic Hormones. Proceedings of Fifth Gonadotrophin Club Meeting, Edinburgh 1966. E. \& S. Livingstone Ltd, Edinburgh and London.

Borth, R., Lunenfeld, B. \& De Watteville, H. (1954) Activite gonadotrope d'un extrait d'urines de femmes en menopause. Experientia, 10, 266.

BRown, J.B. (1968) A rapid method for estimating oestrogens in urine using a semi-automatic extractor. Journal of Clinical Endocrinology, 42, 5.
Brown, J.B., Evans, J.H., Adey, F.D. \& TAFT, H.P. (1969) Factors involved in the induction of fertile ovulation with human gonadotrophins. Journal of Obstetrics and Gynaecology of the British Commonwealth, 76, 289.

ButLeR, J.K. (1967) The assessment of dose requirements of Pergonal. Proceedings of the Royal Society of Medicine, $60,655$.

Butler, J.K. (1969) Time-course of urinary oestrogen excretion after various schemes of therapy with human follicle-stimulating hormone (Pergonal). Proceedings of the Royal Society of Medicine, 62, 34.

Butr, W.R. (1970) Observations on some chemical properties of human follicle-stimulating hormone and on its excretion rate. Proceedings of the Royal Society of Medicine, March, 1968, entitled Development in the Pharmacology and Clinical Uses of Human Gonadotrophins (Ed. by J. K. Butler), pp. 1-7.

Buxton, C.L., Kase, N. \& Van Orden, D. (1963) The effect of human FSH and HCG on the anovulatory ovary. American Journal of Obstetrics and Gynaecology, 87, 773.

Crooke, A.C., Butt, W.R., Palmer, R.F., Morris, R.R., EDWARDS, R.L. \& ANSON, C.J. (1963) Clinical trial of human gonadotrophins. 1 . The effect of pituitary and urinary follicle-stimulating hormone and chorionic gonadotrophin on patients with idiopathic secondary amenorrhoea. Journal of Obstetrics and Gynaecology of the British Commonwealth, 70, 604.

Crooke, A.C., Butt, W.R. \& Betrand, P.V. (1966) Clinical trial of human gonadotrophins. 111. Variation in sensitivity between patients and standardization of treatment. Acta Endocrinologica, Suppl. 111.

Crooke, A.C. (1970) Comparison of the effects of Pergonal and human pituitary follicle stimulating hormone. Proceedings of the Royal Society of Medicine, March 1968, entitled Development in the Pharmacology and Clinical Uses of Human Gonadotrophins (Ed. by J. K. Butler), p.36.

Dicz.falusy, E., Johannisson, E., Tillinger, K.G. \& BETTENDORF, G. (1964) Comparison of the clinical and steroid metabolic effect of human pituitary and urinary gonadotrophins in amenorrhoeic women. Acta Endocrinologica, 90, 35 . 
EshKol, A. \& Lunenfeld, B. (1967) Purification and separation of follicle-stimulating hormone (FSH) and luteinizing hormone (LH) from human menopausal gonadotrophin (HMG). Acta Endocrinologica, 54, 91.

Gemzell, C.A., Diczfalusy, E. \& Tillinger, G. (1958) Clinical effect of human pituitary follicle-stimulating hormone (FSH). Journal of Clinical Endocrinology, 18, 1333.

Gemzell, C. (1964) Induction of Ovulation with Human Gonadotrophins, p. 805. Proceedings from 2nd International Congress of Endocrinology, London. International Congress Series No. 83, Excerpta Medica Foundation, Amsterdam.

Gemzell, C. \& Roos, P. (1966) Pregnancies following treatment with human gonadotrophins. American Journal of Obstetrics and Gynaecology, 94, 490.

Gemzell, C., Carlborg, L., Johansson, E.D.B. \& Roos, P. (1970) Treatment of primary amenorrhoea with human pituitary and chorionic gonadotrophins. Journal of Obstetrics and Gynaecology of the British Commonwealth, $77,58$.

INSLER, V. The fern test in following treatment with human gonadotrophins. Proceedings of the Tel-Hashomer Hospital, 3, 193.

JACOBSEN, A. \& MARShALL, J.R. (1969) Ovulatory response rate with human menopausal gonadotrophins of varying FSH/LH ratios. Fertility and Sterility, 20, 171.

Johannisson, E., Gemzell, C. \& Diczfalusy, E. (1961) Effect of a single injection of human pituitary FSH on urinary estrogens and the vaginal smear in amenorrhoeic women. Journal of Clinical Endocrinology, 21, 1068.

Jones, G., Johanson, A.J., Raiti, S. \& Blizzard, R.M. (1969) Elucidation or normal ovarian physiology by exogenous gonadotrophin stimulation following steroid pituitary suppression. Fertility and Sterility, 20, 14.

Kase, N., Mroueh, A. \& Buxton, C.L. (1968) Pergonal therapy of anovulatory infertility. American Journal of Obstetrics and Gynaecology, 100, 176.

LosTrOH, A.J. \& JoHNSON, R.E. (1966) Amounts of interstitial cell-stimulating hormone and follicle-stimulating hormone required for follicular development, uterine growth and ovulation in the hypophysectomized rat. Endocrinology, 79, 991.

Mozes, M., Bogokowsky, H., Antebi, E. \& Lunenfeld, B. (1965) Thromboembolic phenomena after ovarian stimulation with human gonadotrophins. Lancet, ii, 1213.
Pasetto, N. \& Montanino, G. (1967) Pregnancy after combined HMG-HCG treatment in amenorrhoeic patients. Fertility and Sterility, 18, 685.

Pennington, G.W. \& Hall, R. (1967) The preparation and use of human pituitary gonadotrophin in the treatment of infertility. Journal of Obstetrics and Gynaecology of the British Commonwealth, 74, 902.

Polishuk, W.Z. \& Schenker, J.G. (1969) Ovarian overstimulation syndrome. Fertility and Sterility, 20, 443.

Rabau, E., David, A., Serr, D.M., Mashiach, S., LunenFELD, B. (1967) Human menopausal gonadotrophins for anovulation and sterility. American Journal of Obstetrics and Gynaecology, 98, 92.

Roland, M. (1969) Menotropin with HCG in ovulation induction. Fertility and Sterility, 20, 1004.

Sele, V. \& Starup, J. (1970) Ovarian response to excessive doses of human menopausal gonadotrophin in two patients with primary pituitary insufficiency. Acta Endocrinologica, $65,148$.

ShEARMAN, R.P. (1964) Diagnostic ovarian stimulation with heterologous gonadotrophin. British Medical Journal, 2, 1115.

Shearman, R.P. (1969) Progress in the investigation and treatment of anovulation. American Journal of Obstetrics and Gynaecology, 103, 444.

Swyer, G.I.M., Little, V., Lawrence, D. \& Collins, J. (1968) Gonadotrophin stimulation test of ovarian function. British Medical Journal, 1, 349.

TAYMOR, M.L. \& TAMADA, T. (1967) Immunological relationships between urinary and pituitary follicle-stimulating hormone. Journal of Clinical Endocrinology, 27, 709.

Thompson, C.R., \& Hansen, L.M. (1970) Pergonal (meno tropins): A summary of clinical experience in the inductiop of ovulation and pregnancy. Fertility and Sterility, 21, 844=

Townsend, S.L., Brown, J.B., Johnstone, J.W., Adey, F.D., Evans, J.H. \& TAFT, H.P. (1966) Induction of ovulation. Journal of Obstetrics and Gynaecology of the British Commonwealth, 73, 529.

TYACK, A.J. \& Ellis, J.D. (1971) Management of severe ovarian hyperstimulation. British Medical Journal, 1, 263.

VANDE Wiele, R.L. \& Turksoy, R.N. (1965) Treatment of amenorrhoea and of anovulation with human menopausal and chorionic gonadotrophins. Journal of Clinical Endocrinology, 25, 369.

This Symposium on Anovulatory Infertility was generously supported by G. D. Searle \& Co., High Wycombe, Buckinghamshire, England. 